\section{Agriculture and Public Information in Post-War Bosnia and Herzegovina}

\author{
W. J. M. Heijman - H. A. J. Moll - A. E. J. Wals \\ Department of Social Sciences, \\ Wageningen University
}

\section{BACKGROUND}

Since the Dayton Agreement on Bosnia of 1995 there is peace between Croats, Bosnians and Serbs. Whether this is a lasting situation remains to be seen (de Rossanet, 1997). Pessimists refer to Huntington's "Clash of Civilizations" and argue that because Bosnia is situated on the fault line of the Western and Orthodox civilizations and on top of that has a large muslim minority a new war can not be avoided (Huntington, 1997). Others don't accept this and are of the opinion that rational governance will overcome the problems of the multicultural society. In this view the restoration of the country's economy is a major priority. However, on the long run, a peaceful outcome is not to be taken for granted.

At present, the international community represented by the Office of the High Representative (OHR) in Bosnia and Herzegovina (BiH) controls the political situation and the three ethnic groupes are forced to cooperate. To sustain a lasting peace in the future without the guidance of the OHR the reconstruction of the Bosnian economy starting with the agricultural sector is a precondition. This paper reports on a quick scan carried out in the period 1519 April, 2002, in order to evaluate the possibilities of the agricultural sector as an economic booster in the post war situation. The quick scan was necessary to evaluate and give advise with respect to the plans of the OHR to engage in a public information campaign in order to stimulate the transformation of subsistence farming into commercial agriculture, and to encourage young urban Displaced Persons (DP's) to consider life as a farmer as an option for their future. The campaign will include a number of subregional radio and television series, and a booklet and videos for distribution among the target groups.

Quick scan research here refers to a rapid semisystematic inquiry and validation process involving multiple stakeholders. The semi-systematic inquiry usually involves a document study complemented by focus group discussions, semi-structured and informal interviews. Validation here consisted of soliciting feedback from the participants on the outcomes of the study. Since a quick scan is done under time pressure, the results serve as a semiscientific input for decision-making and further research.

From the above the delegation's task could be formulated as follows: 1 . to describe the specific features of the $\mathrm{BiH}$ agricultural sector, 2. to suggest possible solutions for the apparent problems on the micro level for the short term, and 3. to advise the OHR with respect to the information campaign accordingly.
The analysis is based on a number of intensive meetings with representative stakeholders of the sector. Though the time spent in $\mathrm{BiH}$ was relatively short, thanks to a thorough preparation by the OHR, the delegation was able to acquire a good view of the Strong and Weak points of, and the Opportunities and Threats for the $\mathrm{BiH}$ agriculture and the possibilities of stimulating DP's to return to their region of origin and (re)start their own farm.

The remainder of this paper is organised as follows. Section 2 deals with the Agricultural Sector. As a consequence of the war, not only the physical infrastructure, but also the organisation of production and distribution, has been severely damaged. As a result the sector has to deal with one of the striking features of a post war economy, i.e. the absence of market channels. Section 3 concentrates on the role of public information, communication, and training. Here it will be indicated that in the OHR information campaign one has to take into account at least three different target groups: the existing group of subsistence farmers, the returnees, and the DP's. In Section 4 a number of conclusions will be drawn and advice will be formulated with respect to the information campaign.

\section{THE AGRICULTURAL SECTOR}

The discussions with actors in the agricultural sector ranged from the respective ministers of agriculture of the two entities to consultants, agricultural researchers, staff of processing industries, and to farmers and returnees. ${ }^{1}$ In this section the results of these discussions are brought together under three headings: Agricultural production, Rural organisations, and Market for agricultural products.

\section{Agricultural production}

Production takes place largely by small-scale farmers on farms with an average area of 3 hectares, often subdivided into a number of separated plots. State bodies own a small proportion of the land, 7\%, and their land is either unused, utilised for largescale, mechanised production, or divided into smaller units cultivated by individuals. The land tenure status plays a central role in decisions regarding land utilisation. Pre-war and post-war privatisation, collectivisation and right-of-use arrangements of land and the war situation itself result for many

\footnotetext{
${ }^{1}$ Bosnia and Herzegovina consists of two entities: Republic of Srpska and the Federation of Bosnia and Herzegovina.
} 
individuals in an uncertain situation regarding land ownership or user rights. Such an uncertain situation forms at least a disincentive for investments in land such as drainage, irrigation, land conservation measures, or the establishment of orchards, and in more extreme situations it leads to non-utilisation of land. It was mentioned that a proportion of $50 \%$ of the arable land is presently non-utilised, but this is an estimate in the absence of reliable data.

Agricultural producers and potential producers form a diverse group. A part is experienced in agricultural production as such; a part consists of people who have no experience at all, but who find themselves in a new, rural situation where agricultural production forms at least an option; and the remaining proportion is placed somewhere in between. All groups have in common that experience with the marketing of agricultural produce is minimal or absent, and that access to other agrarian organisations required for commercial agriculture (related to, for example, input supply, access to equipment and financing), is either limited or absent. This places agricultural producers in an isolated situation that leads to an emphasis on production for own consumption, thereby bypassing possibilities for commercial production. The isolation of individual producers, or rural households in general, is aggravated by earlier negative experiences with state dominated co-operatives, and by the war and postwar situation.

\section{Rural organisations}

The history of central planning has left $\mathrm{BiH}$ with an agricultural sector without a developed set of agrarian organisations that enable intensive production and that link producers with consumers. The co-operatives that formed the link in the past have largely ceased operations, and other organisations have apparently not completely taken over their roles in input supply, information, marketing and financing. In this relative vacuum three types of actors operate. Firstly, the private sector in the trade of inputs and in marketing is present, but not able to reach all individual producers with the various services required. Information on the private sector in trade regarding numbers, activities and turnover is not available. Banks do operate in the private sector, but agriculture and especially smallscale agricultural producers are largely outside their field of interest (this is gradually changing). Secondly, a large number of donor supported projects perform services ranging from advice on technology, the organisation of producers for various purposes, the supply of inputs and investment goods, to financing, partly as direct temporary support and partly with a perspective of becoming sustainable and thereby continuous. Thirdly, a number of enterprises in the processing industry of agricultural products like fruits, vegetables and milk do operate and have established links with primary producers on contract basis. These contracts are commercial-oriented and they generally contain a bundle of services like the supply of specialised inputs or investment goods, the supply of information on the production technology and the procurement of produce. These vertical contracts between producers and processors form a valuable approach in the absence of organisations operating in the markets for the various services. For the farmers these contracts form the link with commercial agriculture, and for the processors these contracts ensure the procurement of produce and thus operation at a certain capacity.

Despite the great number of initiatives aimed at closing the gap between the (potential) agricultural producers and the market there seems to be widespread market failures: farmers paper difficulties in selling their products, and processing industries have problems in the procurement of sufficient produce to allow them to fully use their processing capacity. To some extent this gap may be due to the small scale of agricultural production which makes access to the various markets by individual producers difficult, and reaching these individual producers by agrarian organisations costly. This problem of scale could be mitigated by the organisation of producers into farmers' associations, and various projects have followed this strategy with success.

\section{Market for agricultural products}

The national market for agricultural produce is apparently dominated by imports as national production covers $47 \%$ of the demand only. Various explanations were offered for this situation. Firstly an insufficient production capacity of the sub-sectors in vegetables, fruit and dairy. Secondly the lack of competitiveness of domestic production vis-à-vis imported products in terms of both quality and image. The small-scale of the primary production leading to inefficiency in the marketing chain, an insufficient quality orientation of production and the pre-war dominance of the Croatian and Slovenian food-processing industry could be contributing factors. Thirdly the regulatory framework of agricultural inputs as well as food products with its requirements for licensing may favour large-scale imports, as these are more conducive to rent seeking. Probably all three explanations play a role, with a varying relevance for different products.

\section{THE ROLE OF PUBLIC INFORMATION, COMMUNICATION AND TRAINING}

Three key issues emerged from the conversations with key stakeholders: lack of knowledge infrastructure, lack of clarity in terms of the goals, process and contents of public information, communication and training, and the need for target group differentiation. We will discuss all three issues.

\section{Lack of knowledge infrastructure}

Successful agriculture depends a great deal on the understanding (of relationships, environmental impacts, markets, etc.), attitudes (proactive, 
entrepreneurial, positive, future oriented, etc.), skills (technical, financial management, etc.) and on the knowledge (about crops, sustainable land use, markets, bookkeeping, etc.) of the farmers and of those working in the institutions that operate within the chains that link farmers to consumers (food processing industry, farmer representatives, NGOs, etc.). The development of Understanding, Attitudes, Skills and Knowledge (U-ASK) depends on the quality of the agricultural knowledge infrastructure which normally consists of a network of extension services, agri-media, vocational and higher agricultural education, agri-research, and NGO-based as well as industry-based education and training. In the present situation this infrastructure hardly exists, although it must be noted that some NGOs do consider education and training as a part of their agricultural development work and that there is some media attention for agricultural issues aimed at the more general public (mainly through TV and radio).

When developing a knowledge infrastructure one should be mindful of the risk of one-sidedness of institutional learning processes that tend to promote linear and exclusive ways of thinking and ignore the multiple perspectives of all key stakeholders, including those of current active farmers, returnees and displaced people. Sustainable agriculture is, at least in part, achieved by the individual and collective activities of farmers and communities pursuing their own pathways to a quality livelihood (Engel, 1997). With time the facilitation of innovation and empowerment of farmers and rural communities will become as critical as the maximisation of short-term profit and efficiency of food production chains.

\section{Lack of clarity in terms of the goals of public information, communication and training}

A coherent communication strategy provides clarity with regards to its goals (what do we hope to achieve?), process (what instruments do we need to reach our goals?) and contents (what are appropriate themes or topics to address?). The OHR has several options with regards of all three elements. As far as the goals are concerned we can distinguish between more emancipatory goals and more instrumental goals (Heymann \& Wals, 2002). An emancipatory goal would be: to provide displaced people with the necessary U-ASK in order to enable them to make an educated and well-informed decision about whether to (re)turn to agriculture. A more instrumental goal would be to convince displaced people that there is a future in agriculture. Whereas emancipatory goals tend to focus on decision-making skills, critical thinking and increased levels of autonomy and selfdetermination, instrumental goals tend to emphasise the transfer of U-ASK that will move people towards pre- and expert determined destinations. The urgency of the socio-economic situation in the country makes it tempting to focus on more instrumental goals and short-term solutions. At the same time, however, it must be recognised that sustainable livelihoods appear strongly tied to economic viability, equitable natural resource management and social justice. Hence, long term emancipatory approaches towards public information and communication may need to be considered in addition to more short term instrumental ones.

When looking at the process of public information, communication and training it is useful to distinguish different layers of goals and objectives in relation to the various groups the OHR would like to reach. If the emphasis lies on awareness raising (i.e. of farming as a way out of current circumstances or of alternative, more viable, ways of farming) and on providing information on where to get more information, then the use of the abundantly present local radio and TV stations appears very appropriate. Using a programming format that a) provides rich but realistic examples of alternative ways of living and agricultural production, b) allows for identification of the audience with those highlighted in the programme, c) includes dissenting voices as well as consenting voices to promote critical thinking, and d) is supported by a follow-up support mechanism (i.e. support leaflets or manuals, call-in centres or local help desks), will be conducive in motivating people to explore their options. Viewer and listener evaluations and feedback would allow for opportunities to modify and improve the programme.

In addition to mass-media approaches, which, incidentally, could also include feature articles in local newspapers, there is a need for more interactive communication structures at the local level. Once interested people - either those willing to become active farmers or those willing to innovate their current agricultural practice - have been identified, it becomes useful to internally link them (i.e. farmers within the same product line or returnees within the same region or DP's wishing to move back to the same area) in order to provide tailor made, concrete support and to create social networks that can break the pattern of social isolation and individual survival. Facilitated focus groups could meet this need, whereby specific NGOs or local DP offices can possibly play an important co-ordinating role. Some criteria that may be helpful for such follow-up support communication can be found in Annex 1 . While the OHR does not have the capacity to develop these interactive communication structures, it may be well-positioned to identify national and local organisations that are able to (and to some extent already do) fill that void.

The contents of the public information, communication and training should be carefully chosen in close consultation with the target groups. During our initial conversations with a number of stakeholders, a variety of preliminary topics emerged, including: starting up a small business, creating markets, organizing production and creating cooperation, chain awareness, fostering entrepreneurship and economic thinking, writing business plans, 'monitoring input, output and throughput', 'rules, regulations and quality certification', technical support and utilizing human 
resources. Within these topics a distinction can be made between horizontal topics (topics spanning themes that transcend specific product lines and are relevant to all farmers) and vertical topics (topics covering one specific agricultural product using a chain orientation). Again the depth with which these topics are covered will depend on the goals of the communication. Generally speaking when mass media are used, there will be less of an in-depth focus in order to pique the interest of a wider audience and to provide the audience with an attractive appetizer.
In order for such campaign-like activities to be successful there will need to be attention to regional differences, target-group differentiation (there is no such thing as one single audience) and branding (the creation of viewer/listener recognition and identification by using common and frequently returning features and characteristics). In follow-up communication with self-selected groups of people, a more tailor made and in-depth follow-up that does not rely on mass media, but rather on personal contact, is more appropriate.

Some criteria for follow-up communication and training

(Wals \& Bawden, 2000, p. 36)

\begin{tabular}{|c|c|c|}
\hline Criteria & Description & Examples \\
\hline 1. Total immersion & $\begin{array}{l}\text { Fostering a direct experience with an alternative } \\
\text { lifestyle and/or way of farming by allowing } \\
\text { people to discover the inherent possibilities these } \\
\text { alternatives offer }\end{array}$ & $\begin{array}{l}\text { - Taking returnees to areas where people have } \\
\text { successfully converted subsistence farming } \\
\text { into sustainable commercial farming } \\
\text { - Taking individual farmers to successful } \\
\text { farming cooperatives within the same } \\
\text { agricultural sector }\end{array}$ \\
\hline 2. Diversity in learning styles & $\begin{array}{l}\text { Being sensitive to the variety of learning styles } \\
\text { and preferences that can be found both within } \\
\text { groups and in between different groups }\end{array}$ & $\begin{array}{l}\text { - Offering a variety of didactic approaches, } \\
\text { recognizing that literacy levels often are low } \\
\text { - } \\
\text { Reflecting on the learning process with the } \\
\text { learner, creating feedback loops }\end{array}$ \\
\hline 3. Active participation & $\begin{array}{l}\text { Fostering the exchange of ideas, concerns and } \\
\text { knowledge and development of ownership of the } \\
\text { learning process by actively soliciting the } \\
\text { learners' own knowledge and ideas }\end{array}$ & $\begin{array}{l}\text { - Consulting learners on the content of the } \\
\text { learning process by allowing them to identify } \\
\text { key issues and topics } \\
\text { - Supporting learners in their own } \\
\text { experimentation with alternative ways of } \\
\text { living and farming }\end{array}$ \\
\hline 4. A case-study approach & $\begin{array}{l}\text { Digging for meaning by studying an agricultural } \\
\text { production within the whole chain more in-depth } \\
\text { (production, processing, markets, consumers, } \\
\text { etc.) }\end{array}$ & $\begin{array}{l}\text { - Assigning different people to explore } \\
\text { different angles of a particular theme and } \\
\text { bringing the different angles together in a } \\
\text { synthesizing activity }\end{array}$ \\
\hline $\begin{array}{l}\text { 5. Social dimensions of } \\
\text { learning }\end{array}$ & $\begin{array}{l}\text { Mirroring the learner's ideas, experiences and } \\
\text { concerns with those of others through social } \\
\text { interaction }\end{array}$ & $\begin{array}{ll}- & \text { Taking time for discussion and exchange } \\
- & \text { Taking on controversy } \\
- & \text { Stimulating flexibility and open-mindedness } \\
- & \text { Developing a social support network }\end{array}$ \\
\hline 6. Reflective action & $\begin{array}{l}\text { Making the development of reflective action and } \\
\text { action competence an integral part of the learning } \\
\text { process }\end{array}$ & $\begin{array}{l}\text { - Allowing learners to develop their own } \\
\text { course of action and to follow through }\end{array}$ \\
\hline
\end{tabular}

\section{Target group differentiation}

For communication purposes it would be useful to create a classification of target groups. During our conversations with the various stakeholders a number of distinct target groups emerged ${ }^{2}$ : active farmers, returnees, DP's, food processing managers and operators, representatives of agricultural NGOs, and rural development and agri-business policy-makers and legislators. The OHR campaign will target the first three groups in particular. Each of these three groups can be subdivided in more specific ones.

\footnotetext{
2 From an emancipatory perspective it would be better to speak of audiences or, better yet, learners as 'target' suggest a one-directional activity without the possibility of interaction.
}

Returnees and DP's can be subdivided in those who returned or might return to farming (for life) and those who consider farming as a (temporary) stepping stone to a life outside of farming. Active farmers can be subdivided in those who are engaged in subsistence farming, those who are engaged in commercial farming or in organic farming, those with some formal education and training and those without, those engaged in dairy farming or in fruit /or vegetable farming, and so on. If the different subgroups cannot be addressed in separate media series, at least the different (parts of) shows should be earmarked clearly. Target group differentiation of all intended audiences is particularly important in the follow-up support strategy in order to allow for customized, needs-based, education, communication and training (Leeuwis \& van den Ban, in press). 


\section{CONCLUSIONS AND RECOMMENDATIONS}

In order to be successful in making an economic booster out of the sloppy Bosnian agricultural sector a lot can be done. In this section recommendations are given for the two areas covered: the agricultural sector and the role of public information, communication, and training.

\section{With respect to the agricultural sector}

The availability of unused or under-utilised land and the high level of unemployment in rural areas lead to the conclusion that agriculture offers in principle scope for employment and thus for income generation. It is unlikely that agriculture alone can provide for full employment, but it can certainly substantially contribute to employment without substantial investments at short notice.

The small size of the individual farms makes it necessary to concentrate on agricultural production with a high added value per unit of area. Horticultural production (vegetables, flowers and fruit) and dairy production are the logical enterprises, and it is not surprising that these enterprises are firmly established in various regions. Seen the level of imports, and the unfulfilled demand for produce by domestic processors, there are ample opportunities to expand the production in these sub-sectors.

A second consequence of the small scale of agricultural production is the need to organise farmers in larger units. Co-operatives bear the burden of past experience, and farmers associations are apparently the preferred option. Associations allow for more freedom of organisation and are easier to establish than co-operatives. Various examples of promising associations were encountered during the mission.

The absence or weak functioning of a range of rural organisations in input supply, financing, information, and marketing makes it difficult for farmers and farmers' associations to take the step towards commercial agricultural production. Especially the absence of a well functioning financial market for small farmers is a feature of post war economies (Addison et al., 2001a and 2001b). The mechanism of contract farming deals with a combination of the various services and forms thereby a solution for the present market failures.

Summarising we may say that there are a number of constraints in agriculture with regard to land ownership, scale of production, rural organisations and international competition. Dealing with these constraints means structural change within the agricultural sector and within the national economy, and this is a long-term affair. However, there are a number of possibilities to cope with the present constraints through vertical integration, i.e. contract farming, and through horizontal integration, the organisation of farmers in associations (for a number of examples see Annex 1). These coping strategies result in short-term possibilities for an expansion of commercially oriented agricultural production, and they could form the central themes in the planned Programme on Agricultural Development.

\section{With respect to public information, communication, and training}

A two step-approach towards public information, communication and training is needed. The first level, the public information step, is based on the use of local radio and television that highlights the potential of agriculture by showing inspiring examples in an appetizing but realistic way, and by inviting interested people to explore their options by pointing them towards local information desks and/or call-in centers. This first step is most urgently needed in order to pave the way for more targeted follow-up activities. The second step, the communication and training step, is based on more interactive approaches and the development of specific understanding, attitudes, skills and knowledge (U-ASK) and is part of a supportive knowledge infrastructure to which people can always turn as they seek to improve their situation.

This support structure will gain in importance as more and more people become attracted to sustainable agriculture as a result of step one. This emerging support structure will need to have outlets at the rural community level in order to be in tune with the knowledge, ideas and concerns of the community membership. At the same time this support structure has to provide links between farmers (intra group communication) and between farmers, food processing industry and markets (inter group communication). While both steps each have their own communication criteria, and can, technically speaking, be developed independently, the simultaneous development of both would be preferred. In other words, the OHR should initiate and develop a targeted information campaign in the short term, but at the same time should start thinking about the launching of knowledge infrastructure building activities as part of step two or, at least should identify key actors who could take on responsibility for follow-up communication and training. From our initial observations it can be concluded there are quite a few organizations that are well positioned to play an active role in both steps, however we do feel more explorative research needs to be done to get a more balanced and complete view of possible partners in the country.

Although we did not look specifically at the state of the country's education system, there may be opportunities to infuse agriculture and rural development in the curriculum of state schools as the education system is relatively intact. Furthermore it is foreseeable that newly formed local DP offices may play a role in initial education and training of those considering to return to the rural areas and to become farmers. In addition we have come across a number of links between vocational agricultural schools from abroad with institutions in the country that promote and conduct education and training for farmers, that may be promising and worthwhile 
expanding. In addition, support by means of TEMPUS funded exchange projects may be useful in improving the knowledge infrastructure and the quality of the information exchanged.

\section{REFERENCES}

Addison T.-P. le Billon-S. Mansoob Murshed (2001a): Finance in Conflict and Reconstruction. World Institute for Development Economics Research. WIDER Discussion Paper, August

Addison T.-A. Geda-P. le Billon-S. Mansoob Murshed (2001b): Financial Reconstruction in Conflict and 'Post-Conflict' Economies. World Institute for Development Economics Research. WIDER Discussion Paper, September

Engel, P. G. H. (1997): The Social Organisation of Innovation: a focus on stakeholder interaction. Amsterdam: Royal Tropical Institute (KIT)

Heymann, F.-A. E. J. Wals (2002): Cultivating Conflict and Pluralism through Dialogical Deconstruction. In: Leeuwis, C.R. Pyburn (Eds.) Wheelbarrows full of frogs: social learning in resource management. Van Gorcum, Assen
Huntington S. P. (1997): The Clash of Civilizations and the remaking of World Order. Touchstone, London

Leeuwis, C.-A. van den Ban (in press). Communication for Innovation in Agriculture and Rural Resource Management: Building on the tradition of agricultural extension. Oxford, Blackwell Science

Rossanet B. de (1997): War and Peace in the Former Yugoslavia. Nijhoff Law Specials, 33. Kluwer, The Hague

Wals, A. E. J. \& Bawden, R. (2000): Integrating sustainability into agricultural education: dealing with complexity, uncertainty and diverging worldviews. Gent: ICA 